\title{
Suppressing the oxygen ingress into Ti-alloys by a one-step Al- plus F-treatment
}

\author{
Alexander Donchev, Mathias Galetz
}

DECHEMA-Forschungsinstitut

Theodor-Heuss-Allee 25; D-60486 Frankfurt/Main, Germany

\begin{abstract}
Oxygen ingress into technical Ti-alloys during high temperature exposure in oxygen containing environments leads to an enriched surface zone due to the high oxygen solubility in titanium. This affected zone is known as alpha case and is embrittled compared to the substrate material. Therefore, the operating temperature of these alloys is limited. An enrichment of Al in the surface zone of Ti-alloys leads to an improvement by the formation of intermetallic $T_{i} A l_{y}$-phases with decreased oxygen solubility. This one-step Al-enrichment plus a F-treatment is proposed for the formation of a continuous stable alumina scale which prevents oxygen inward diffusion. In this paper the results of high temperature exposure tests in air of technical Ti-alloys are presented without any treatment and treated with Al-enrichment including fluorination. Post experimental investigations such as SEM reveal the formation of thin alumina layers on treated samples. Hardness measurements confirm that no embrittlement was observed for the treated samples while untreated specimens show increased hardness values in the subsurface zone corresponding with the oxygen inward diffusion profile.
\end{abstract}

Keywords: Titanium alloys, aluminization, fluorine effect, high temperature oxidation

\section{$\underline{\text { 1. Introduction }}$}

Titanium alloys are widely used as structural materials in several ambient temperature applications [1]. However, their high affinity to oxygen can cause problems during high temperature exposure [2]. The rutile layer which is formed in the presence of oxygen protects the base material at lower temperatures but it loses its barrier properties due to an increased disorder of the $\mathrm{TiO}_{2}$-lattice [3]. Therefore, the diffusion through this scale is easy and oxygen becomes enriched in the subsurface zone due to its high solubility in the a-Ti phase [4]. This leads to a brittle subsurface zone, alphas case, which reduces the lifetime of Ti-components [5]. Hence Ti-alloys cannot be used at temperatures above approximately $600^{\circ} \mathrm{C}$. To overcome this problem a new concept is presented in this paper. The established route of aluminizing Ti-alloys is combined with the fluorine effect. This effect was first established for intermetallic TiAl alloys with an Al-content between 40 and 50 at.\% [6]. Those alloys usually form a mixed oxide/nitride scale $\left(\mathrm{TiO}_{2} / \mathrm{Al}_{2} \mathrm{O}_{3} / \mathrm{TiN}\right)$ during high temperature oxidation in oxidizing atmospheres [7]. The thermodynamic stabilities of Ti- and Al-oxide are similar and the Al-activity is much lower than the one of Ti so that both oxides are formed side-by-side [8]. This mixed scale mechanism is changed by addition of defined amounts of fluorine so that a protective alumina layer is formed [9]. In this paper this so called fluorine effect is transferred to Ti-alloys with no Al at all or a lower Al-content. After Al-enrichment of the surface zone the Al-content is high enough to get the fluorine effect to operate. The Al-enrichment by the powder pack process (aluminization) leads to the formation of an intermetallic $\mathrm{Ti}_{\mathrm{x}} \mathrm{Al}_{\mathrm{y}}$-diffusion zone which is not susceptible to Ti-fire [2] and has low oxygen solubility [10]. Additionally the TiAl diffusion zone is enriched with small amounts of fluorine at the surface which get the F-effect 
to operate. Results of high temperature oxidation tests show the positive effect of the one-step treatment. Post experimental investigations of metallographic cross sections are used to characterize the scales. The positive effect on the environmental stability will be discussed in the view of a technical application of the treatment for Ti-components to be used at elevated temperatures in oxidizing environments.

\section{Material and experiments}

Specimens of 2 Ti-based materials (Table 1) were machined into $10 \times 10 \times 1 \mathrm{~mm}^{3}$ coupons. The coupons were ground with $\mathrm{SiC}$-paper before any further treatment to 1200 grit, ultrasonically cleaned with ethanol, wiped with a soft tissue and dried at room temperature (RT). Al-enrichment was performed via the powder pack process. Specimens were stored in a sealed alumina crucible packed in an $\mathrm{Al} / \mathrm{NH}_{5} \mathrm{~F}_{2} / \mathrm{Al}_{2} \mathrm{O}_{3}$-powder mixture so that besides aluminization also fluorination was achieved in a one step process. The mixture was heated to $700^{\circ} \mathrm{C}$ under a steady stream of Ar for $5 \mathrm{~h}$. Such treated samples were thermo-cyclically oxidized at $700^{\circ} \mathrm{C}$ in air to investigate their oxidation behavior under thermal cycling conditions. One cycle consisted of $24 \mathrm{~h}$ hot dwell at temperature and $1 \mathrm{~h}$ cold dwell at RT. Heating up and cooling down took place within approximately $10 \mathrm{~min}$. Their performance was compared with that of the bare materials. Post experimental investigations included metallographic preparation, light optical microscopy (LOM), scanning electron microscopy (SEM) with energy dispersive X-ray spectroscopy (EDX) and electron micro probe analysis (EPMA). Metallographic preparation included galvanic nickel plating at RT to protect the scales during hot embedding within an epoxy resin and polishing. Hardness measurements were performed with a micro indenter according to Vickers (HV). 4-point bend tests were performed on rectangular specimens with $80 \times 5 \times 3 \mathrm{~mm}$ size.

Table 1. Compositions of the investigated alloys (wt.\%)

\begin{tabular}{|c|c|c|c|}
\hline Alloy & Ti-content & Additional elements & Phases \\
\hline $\mathrm{Cp}-\mathrm{Ti}$ & 99.4 & $0.3 \mathrm{O}-0.3 \mathrm{Fe}$ & $\mathrm{a}$ \\
\hline $\mathrm{Ti} 6242$ & 86 & 6Al-2Sn-4Zr-2Mo & $\mathrm{a}+\mathrm{b}$ \\
\hline
\end{tabular}

\section{Results and discussion}

The mass change behavior of the untreated alloys obtained during the thermocyclic exposure test is presented in Figure 1. The mass change data of the a-Ti alloy show some mass losses which are caused by the spallation of parts of the oxide scale which can be seen in the macroscopic image (Fig. 2a). This image reveals a yellow oxide scale. The spalled areas are again covered by an oxide scale. The mass change curve of the Ti6242 sample is steady and lower compared to the one of $\mathrm{Cp}$-Ti but spalled areas are visible in the macroscopic image (Fig. 2b). Hence, the mass gain by oxidation was higher than the mass loss by spallation. Additional information is obtained from metallographic cross sections. In Figure 3 (a, b) LOM images of the cross sections of the exposed untreated specimens are presented. The spallation is clearly visible (Fig. 3a, b). The Ni plating has penetrated the partly spalled oxide layer so that the remaining oxide can be found in between (Fig. $2 \mathrm{~b}$ ). 


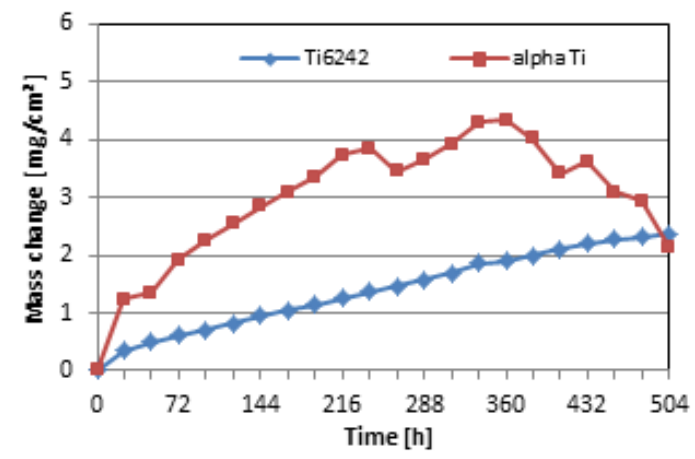

Figure 1. Mass change behavior of the untreated alloys during thermocyclic exposure for $504 \mathrm{~h}$ at $700^{\circ} \mathrm{C}$ in air.
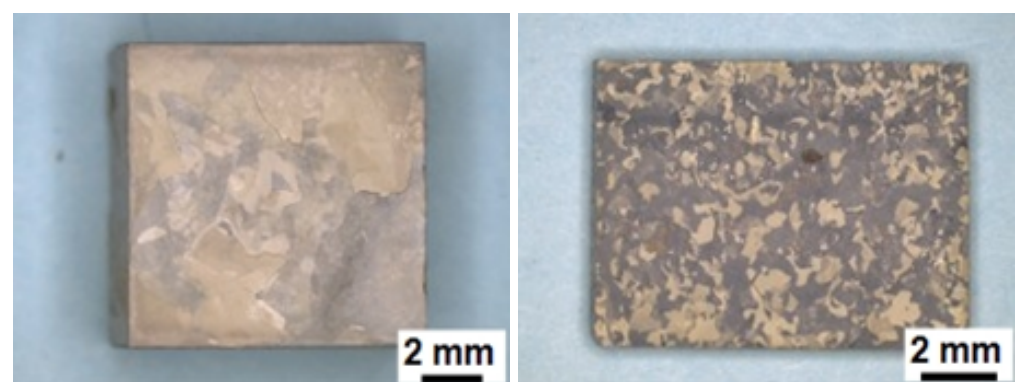

Figure 2a, b. Macroscopic images of the samples after $504 \mathrm{~h}$ of exposure at $700^{\circ} \mathrm{C}$ in air, a $=\mathrm{Cp}$-Ti, $\mathrm{b}=\mathrm{Ti} 6242$.
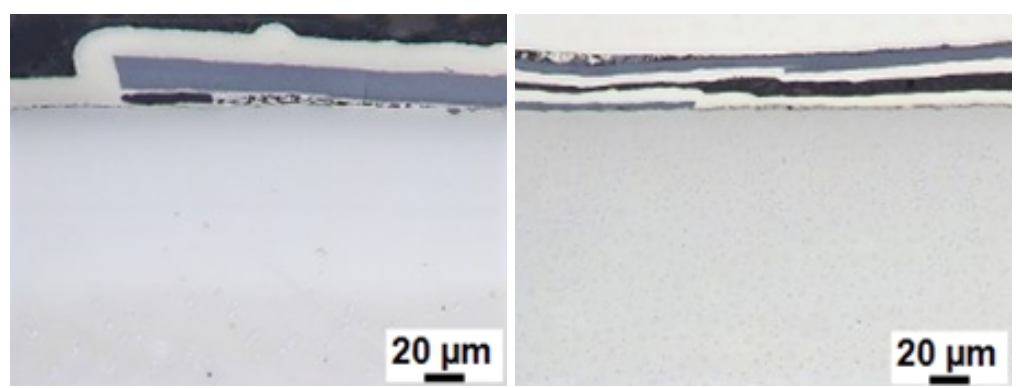

Figure 3a, b. LOM images of the metallographic cross sections after $504 \mathrm{~h}$ of exposure at $700^{\circ} \mathrm{C}$ in air, a $=\mathrm{Cp}-\mathrm{Ti}, \mathrm{b}=\mathrm{Ti6242}$.

SEM investigations show the oxide scales and the spallation in more detail. The scales of Cp-Ti and Ti6242 show similar morphology. The remained $\mathrm{TiO}_{2}$ oxide scale on the Ti-substrate is porous and about $15 \mu \mathrm{m}$ thick (Fig. 4a). At the interface oxide/substrate a crevice is visible and the outer subsurface zone of the substrate reveals cracks. $\mathrm{The}^{\mathrm{TiO}} \mathrm{O}_{2}$ layer on the Ti6242 sample is slightly thinner (Fig. 4b). The oxide scale exhibits a layered structure due to the cyclic exposure which is partly spalled. The attachment towards the substrate is very loose. There are cracks parallel and perpendicular to the interface. 


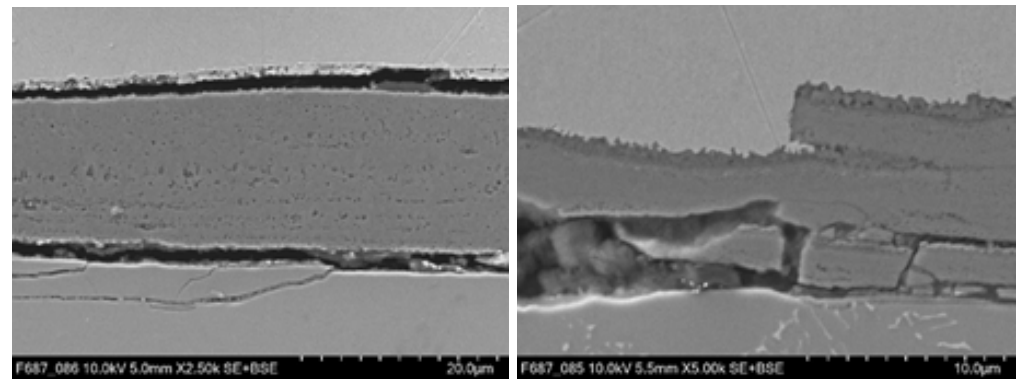

Figure 4 a, b. SEM-images of the metallographic cross sections of $\mathrm{Cp}$-Ti (a) and Ti6242 (b) oxidized for $504 \mathrm{~h}$ at $700^{\circ} \mathrm{C}$ in air.

The EPMA/BSE images (Fig: 5a, 6a) do not show any oxygen uptake of the materials but the depth profile analyses reveal the $\mathrm{TiO}_{2}$ scale formation and the oxygen ingress into Cp-Ti (Fig. 5b) and Ti6242 (Fig. 6b). Oxygen diffusion profiles were found underneath the $\mathrm{TiO}_{2}$ layer. The oxygen diffusion reaches more than $100 \mu \mathrm{m}$ in depth into the Cp-Ti sample (Fig. 5) while the oxygen diffusion into Ti6242 does not exceed about $80 \mu \mathrm{m}$ (Fig. 6). The measurements were taken at areas where the oxide scales were still attached to the substrate. Their thicknesses are $17 \mu \mathrm{m}$ for $\mathrm{Cp}$-Ti and $7 \mu \mathrm{m}$ for Ti6242.
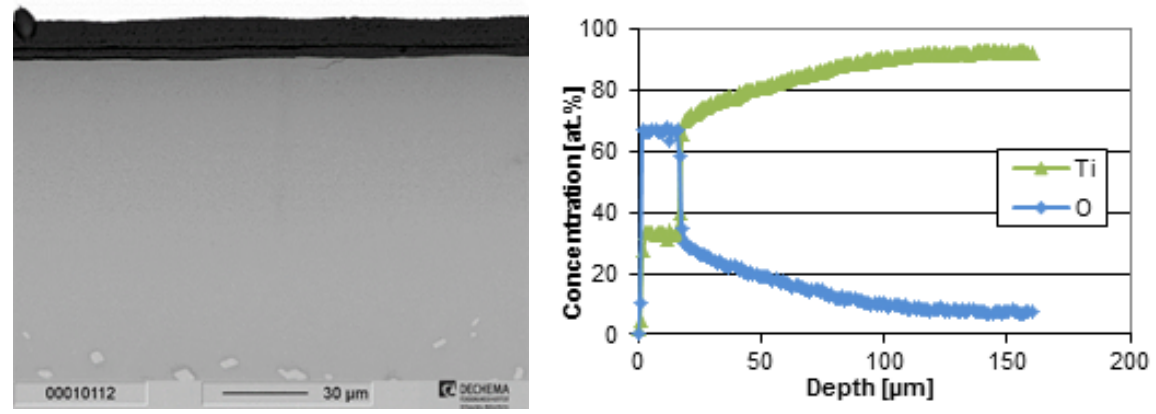

Figure 5. EPMA/BSE image (a) and EPMA-depth profiles (b) of an untreated Cp-Ti sample after 504 h cyclic of oxidation at $700^{\circ} \mathrm{C}$ in air.
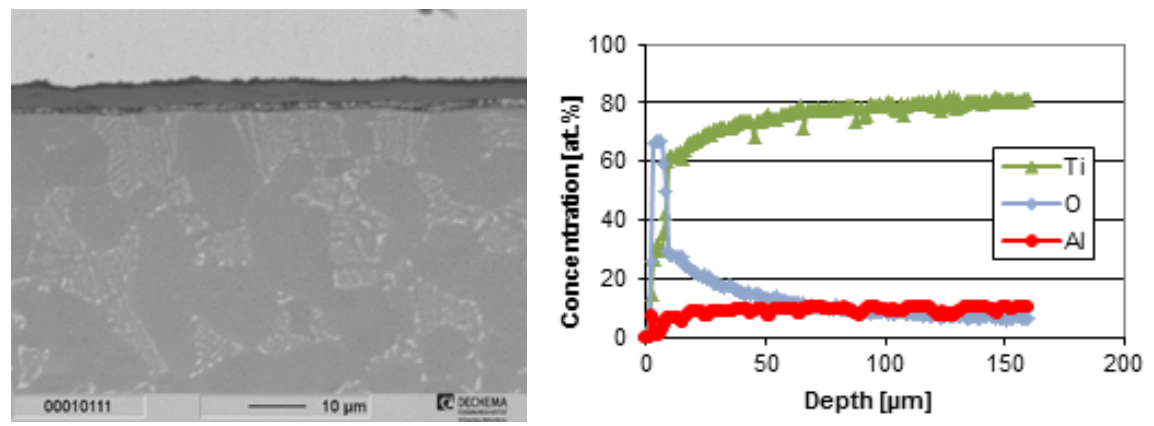
Figure 6. EPMA/BSE image (a) and EPMA-depth profiles (b) of an untreated Ti6242-sample after 504 h of cyclic oxidation at $700^{\circ} \mathrm{C}$ in air.

The EPMA elemental images exhibit the effects of exposure on the microstructure of the subsurface zone in the untreated $\mathrm{Cp}$-Ti sample. Iron which is evenly distributed within the whole material before exposure was found enriched underneath the oxygen affected zone, i.e. at about $120 \mu \mathrm{m}$ depth (Fig. 7b). The inward diffused oxygen has induced formation of some Fe-rich zone.

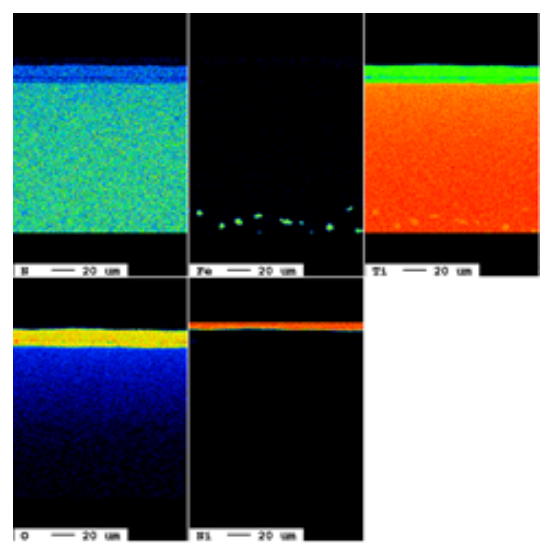

Figure 7a-e. EPMA-elemental images of $\mathrm{N}(\mathrm{a}), \mathrm{Fe}(\mathrm{b}), \mathrm{Ti}(\mathrm{c}), \mathrm{O}(\mathrm{d})$ and $\mathrm{Ni}(\mathrm{e})$ in the sub surface zone of an untreated $\mathrm{Cp}$-Ti sample after504 $\mathrm{h}$ oxidation at $700^{\circ} \mathrm{C}$ in air $($ red $=$ high amount, blue $=$ low amount $)$.

The homogeneous oxygen ingress into the untreated Ti6242 specimen has not dissolved the b-phase, so far (Fig. 8). The Mo-rich phase is still visible directly underneath the oxide sale (Fig. 8b). Some Al enrichment can be found in the oxide but this enrichment does not reflect a protective alumina layer and, therefore, does not prevent oxygen ingress (Fig. 8h). Oxygen is an alpha stabilizing element. Hence, we can suspect finally dissolution of the b-phase and an effect on the mechanical properties after longer exposure times.

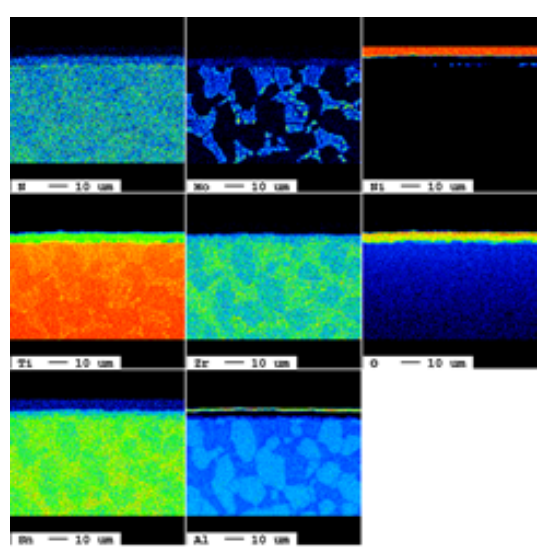


Figure 8a-h. EPMA-elemental images of N (a), Mo (b), Ni (c), Ti (d), Zr (e), O (f), Sn (g) and Al (h) in the sub surface zone of an untreated Ti6242 sample after504 $\mathrm{h}$ oxidation at $700^{\circ} \mathrm{C}$ in air.

The one-step treatment leads to a much lower mass change behavior compared to the untreated materials which is steady over the whole period of exposure (Fig. 9). The final mass gain values of the two treated samples are almost equal and stay below $1 \mathrm{mg} / \mathrm{cm}^{2}$.

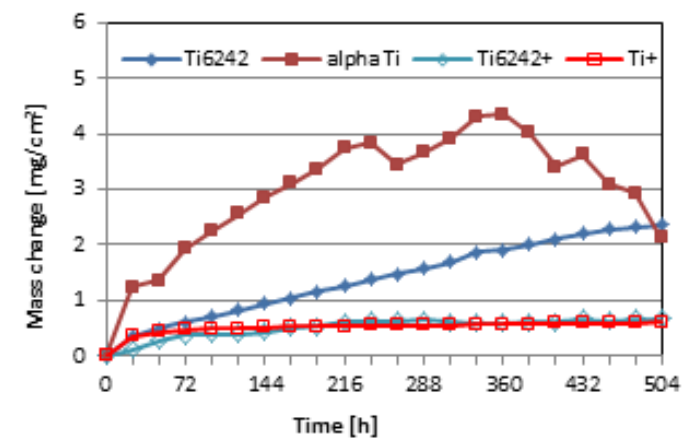

Figure 9. Mass change behavior of the untreated and treated alloys during thermocyclic exposure for $504 \mathrm{~h}$ at $700^{\circ} \mathrm{C}$ in air.

An intermetallic $\mathrm{TiAl}_{3}$ diffusion layer was formed on the alloys via the one-step powder pack process. The thickness of the diffusion zone is influenced by the pack parameters, i.e. temperature or composition. After optimization a less than $10 \mu \mathrm{m}$ thin, crack free $\mathrm{TiAl}_{3}$ layer was formed. This was found on all substrates. Hence, only one image is shown here (Fig. 10a). The composition of the diffusion zone was proven by EDX and EPMA (Fig. 10b). The interface of the diffusion layer and the substrate is smooth and without pores. The surface of the diffusion zone is rough. This indicates an outward growth of the coating layer.
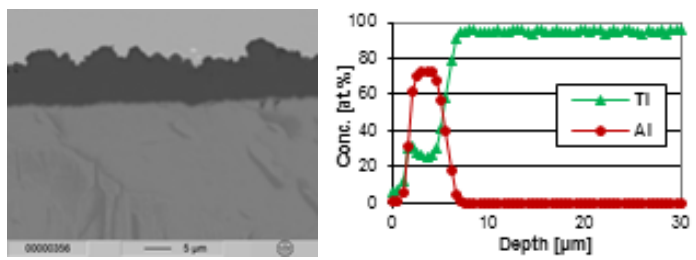

Figure 10a, b. EPMA/BSE image (a) and EPMA depth profiles (b) of a treated Ti-sample optimized one-step treatment.

The oxidation behavior of the treated samples differs from the one of the untreated specimens. On the surface of the treated Cp-Ti sample a thin alumina layer has formed (Fig. 11a). No spallation of the oxide occurred. The diffusion layer underneath is still intact with no cracks and its Al-content has only slightly dropped due to Al-oxide formation and interdiffusion with the substrate. No oxygen is found within and underneath the diffusion zone in the surface zone of the substrate. This was verified by EPMA (Fig. 11b). Hence, no oxygen affected zone has formed. 

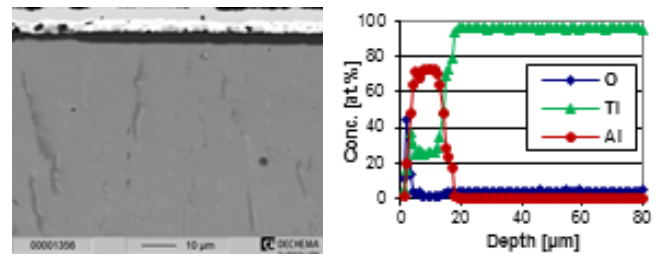

Figure 11a, b. EPMA/BSE image (a) and EPMA depth profiles (b) of a treated Ti-sample after504 $\mathrm{h}$ oxidation at $700^{\circ} \mathrm{C}$ in air

The results for Ti6242 are similar (Fig. 12). The $\mathrm{Al}_{2} \mathrm{O}_{3}$ layer is thin and attached to the diffusion zone.
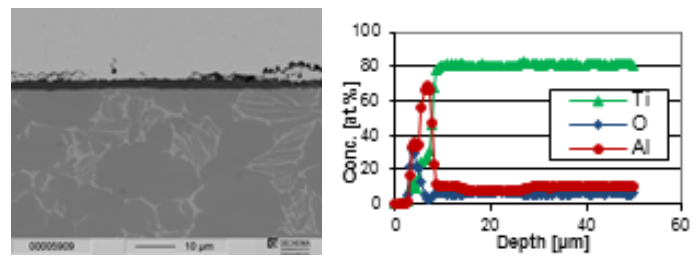

Figure 12a, b. EPMA/BSE image (a) and EPMA depth profiles (b) of a treated Ti6242-sample after504 $\mathrm{h}$ oxidation at $700^{\circ} \mathrm{C}$ in air

At the interface towards the substrate the different intermetallic phases in the order of a decreasing Al-content are found $\left(\mathrm{TiAl}_{2}, \mathrm{~g}-\mathrm{TiAl}\right.$ and $\left.\mathrm{a}_{2}-\mathrm{Ti}_{3} \mathrm{Al}\right)$. Those layers are about 1-2 $\mu \mathrm{m}$ thin (Fig. 13). Directly at the interface towards the substrate also some pores are locally visible (Kirkendall voids).

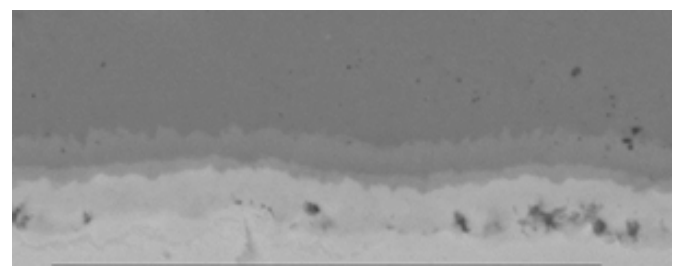

Figure 13. SEM image of the interdiffusion zone of the exposed Cp-Ti sample after $504 \mathrm{~h}$ oxidation at $700^{\circ} \mathrm{C}$ in air

The oxygen affected zone possesses a much higher hardness than the substrate. Figure 14 shows the hardness profiles of the untreated and treated Cp-Ti-samples after 504h of thermocyclic oxidation at $700^{\circ} \mathrm{C}$ in air which correlates directly with the oxygen concentration profiles. For the untreated sample the measured hardness reaches up to $700 \mathrm{HV} 0.01$ directly underneath the oxide scale. Here the oxygen content in the material is the highest while the hardness of the substrate is only about $250 \mathrm{HV} 0.01$. The oxygen content shows a diffusion profile starting at about 30 at.\% underneath the oxide scale. No oxygen ingress, hereafter, no hardness change was measured for the treated sample. 


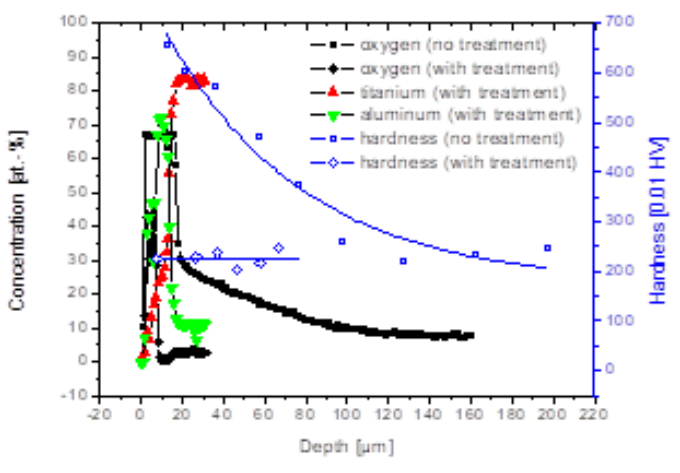

Figure 14. Hardness profiles and corresponding depth profiles of the relevant elements of the untreated and treated Cp-Ti samples after 504h oxidation at $700^{\circ} \mathrm{C}$ in air.

The protective alumina layer formed on the thin diffusion layer is stabilized by the presence of small amounts of fluorine. This stabilization of the $\mathrm{Al}_{2} \mathrm{O}_{3}$-layer via the so-called fluorine-effect is essential. Otherwise $\mathrm{TiO}_{2}$ will also form if the $\mathrm{Al}$ content drops to a critical value due to interdiffusion with the substrate and outward diffusion of Al due to alumina formation. This would deteriorate the protective effect of the alumina layer and finally lead to the formation of a nonprotective mixed oxide scale $\left(\mathrm{TiO}_{2} / \mathrm{Al}_{2} \mathrm{O}_{3}\right)$. The fluorine effect triggers the exclusive formation of $\mathrm{Al}_{2} \mathrm{O}_{3}$ during high temperature oxidation of intermetallic TiAl-alloys if a defined fluorine concentration is adjusted at the metal surface. This necessary concentration was thermo-dynamically calculated in advance [9] and the effect was proven experimentally [11]. $\mathrm{The} \mathrm{Al}_{2} \mathrm{O}_{3}$-layer formed on F-treated specimens is stable under thermocyclic conditions up to several thousand hours even with the $\mathrm{a}_{2}-\mathrm{Ti}_{3} \mathrm{Al}$ phase underneath [12]. This is in contrast to high temperature oxidation tests of the a2-phase which usually forms a thick mixed scale rich in titania [13]. Furthermore it has high oxygen solubility [10]. The aluminum activity in these materials is too low to form alumina but via the fluorine effect the formation of a- $\mathrm{Al}_{2} \mathrm{O}_{3}$ is triggered even at temperatures well below $1000^{\circ} \mathrm{C}$ where on e.g. Ni-based materials metastable g- $\mathrm{Al}_{2} \mathrm{O}_{3}$ is formed [14]. This can be seen in a XRD-spectrum of a treated and exposed Ti 6242 specimen (Fig. 15). The spectrum reveals only the peaks of the intermetallic aluminides and $\mathrm{a}-\mathrm{Al}_{2} \mathrm{O}_{3}$. This result was achieved despite the rather low temperature of $700^{\circ} \mathrm{C}$ compared to the higher temperatures needed for a-alumina formation on Fe- or Ni-base alloys [15].

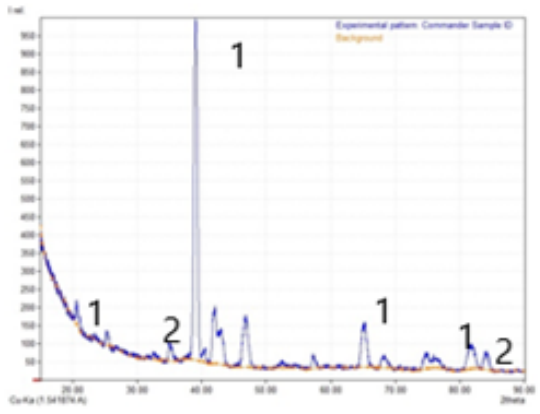

Figure 15: XRD-spectrum of a treated Ti6242 sample after exposure at $700^{\circ} \mathrm{C}$ for $120 \mathrm{~h}$ in air $\left(1=\operatorname{Ti}_{x} \mathrm{Al}_{\mathrm{y}}, 2=\mathrm{Al}_{2} \mathrm{O}_{3}\right)$ 
Exposure tests up to $1200 \mathrm{~h}$ have been performed on samples which were aluminized and fluorine treated afterwards in a two-step treatment [16]. Those results were the same as for the here shown one-step treatment so that no results from exposure tests exceeding $600 \mathrm{~h}$ are presented in this work. The thin aluminide diffusion zone $(<5 \mu \mathrm{m})$ was depleted in aluminum down below 60 at.\% and the alumina layer was still intact. Long term investigations are ongoing to see when the $\mathrm{Al}$ content in the surface zone will drop below 25 at.\%. These results will be presented elsewhere.

Investigations of the mechanical behavior have been performed in form of 4-point bending tests. The -point bending tests did not show any effect of exposure and/or the treatment. The Ti substrate is very ductile so that a ca. $100 \mu \mathrm{m}$ broad affected zone could not be seen with our equipment because the limits of our machine were reached without breaking any specimen whether it was exposed with or without treatment. The sample thickness was $3 \mathrm{~mm}$ so that the unaffected cross section determined the bending behavior.

The Al-enrichment via the powder pack process is a widely used method for improving the environmental stability of steel components and components made of Ni-base alloys. The adjustment of the process to Ti-components is easy to accomplish. Therefore, the implementation of the treatment described in this paper for Ti-components should be possible to upscale industrially in a rather short period of time without too many difficulties.

\section{Acknowledgements}

The authors would like to thank the German Ministry of Economics and Technology (BMWi) for funding the project via the German Federation of Industrial Research Associations (AiF). Support of GfE, RollsRoyce Germany and ThyssenKrupp for providing the materials is also gratefully acknowledged by the authors.

6. References

[1] F.H. Froes, T.-L. Yau, H.G. Weidinger, Materials Science and Technology Vol. 8, ed. R.W. Kahn, P. Haasen, E.J. Kramer, VCH Weinheim 1996 p.399

[2] M. Peters, J. Kumpfert, C.H. Ward, C. Leyens, Titanium and Titanium Alloys, ed. C. Leyens, M. Peters, Wiley-VCH Weinheim 2003 p. 333

[3] R.I. Jaffee, H.M. Burte, Titanium Science and Technology, Plenum Press New York 1973

[4] C. Leyens, Titanium and Titanium Alloys, ed. C. Leyens, M. Peters, Wiley-VCH Weinheim 2003 p. 189

[5] G. Lütjering, J.C. Williams, Titanium, Springer Berlin 2003 p. 48

[6] M. Hald, M. Schütze, Materials Science Forum, 1997, 251-254, 179-186

[7] A. Rahmel, W.J. Quadakkers, M. Schütze, Materials and Corrosion, 1995, 1995: pp.271-285

[8] A. Rahmel, P.J. Spencer, Oxidation of Metals, 1991, 35: pp.53-68 
[9] A. Donchev, B. Gleeson, M. Schütze, Intermetallics 2003, 11: pp.387-398

[10] J.L. Smialek, J.A. Nesbitt, W.J. Brindley, M.P. Brady, J.K. Doychak, R.M. Dickerson, D.R. Hull, Materials Research Society Symposium Proceedings, 1995, 364: pp.1273-1284

[11] A. Donchev, E. Richter, M. Schütze, R. Yankov, Journal of Alloys and Compounds, 2008, 452: pp. 7-10

[12] F. Dettenwanger, M. Schütze, Oxidation of Metals, 2000, 54, 121-138

[13] A. Donchev, M. Schütze, Materials Science Forum, 2010, 638-642: pp. 1294-1299

[14] V.K. Tolpygo, D.R. Clarke, Materials at High Temperatures 17 (2000) 59-70

[15] H. Al-Badairy, D.J. Prior and G.J. Tatlock, Materials at High Temperatures 22 (2005) 453-460

[16] A. Donchev, M. Schütze, A. Kolitsch, R. Yankov, TMS 2014 Supplemental Proceedings, TMS Hoboken 2014 p. 79

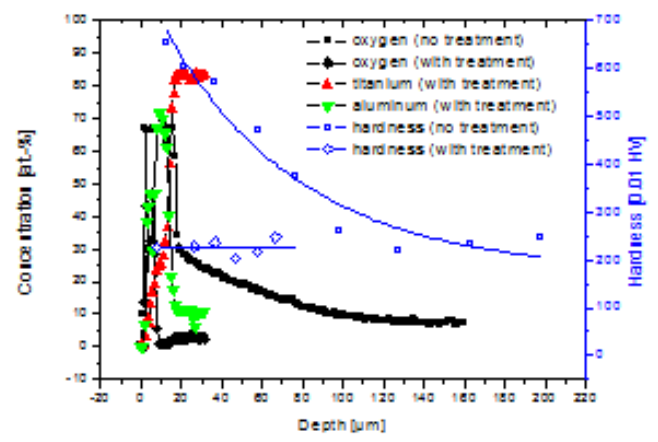

